\title{
Disparities in Students' Propensity to Consent to Learning Analytics
}

\author{
Warren Li · Kaiwen Sun • Florian \\ Schaub • Christopher Brooks
}

Received: date / Accepted: date

\begin{abstract}
Use of university students' educational data for learning analytics has spurred a debate about whether and how to provide students with agency regarding data collection and use. A concern is that students opting out of learning analytics may skew predictive models, in particular if certain student populations disproportionately opt out and biases are unintentionally introduced into predictive models. We investigated university students' propensity to consent to learning analytics through an email prompt, and collected respondents' perceived benefits and privacy concerns regarding learning analytics in a subsequent online survey. In particular, we studied whether and why students' consent propensity differs among student subpopulations by sending our email prompt to a sample of 4,000 students at our institution stratified by ethnicity and gender. 272 students interacted with the email, of which 119 completed the survey. We identified that institutional trust, concerns with the amount of data collection versus perceived benefits, and comfort with instructors' data access were key determinants in students' decision to participate in learning analytics. We find that students identifying ethnically as Black were significantly less likely to respond and self-reported lower levels of institutional trust. Female students reported concerns with data collection but were also more comfortable with use of their data by instructors . Students' comments corroborate these findings and we discuss the implications of these concerns on educational data collection.
\end{abstract}

W. Li

School of Information

University of Michigan

105 S. State St.

Ann Arbor MI, 48104, USA

E-mail: liwarren@umich.edu

K. Sun · E-mail: kwsun@umich.edu

F. Schaub·E-mail: fschaub@umich.edu

C. Brooks· E-mail: brooksch@umich.edu 
Keywords privacy · consent · learning analytics · educational equity · institutional trust

\section{Introduction}

In recent years, there has been increasing amounts of data collection in educational settings. This is largely attributed to the rise of technology use in classrooms (Tondeur et al., 2017; Long et al., 2017). Coupled with advances in artificial intelligence and machine learning algorithms which heavily rely on large quantities of data, vast insights into students' lives such as study behaviors (Jovanović et al., 2017), cognitive processes (Ritter et al., 2007), and other factors conducive to learning (Baker et al., 2015) can be gained. One purpose for the collection and use of this data is to create predictive models of learners, the targets of which range from academic performance to affect and engagement in class (Gardner and Brooks, 2018). There are many potential benefits to such models, such as improving an institution's or instructor's ability to know when particular interventions should take place (Miller et al., 2009). An application of these models include early warning systems (Arnold and Pistilli, 2012), which are used to alert advisors, instructors, administrators, or students themselves if a student appears to be struggling so that they can be supported before they fall significantly behind (Alhadad et al., 2015).

However, these systems often rely upon the collection of sensitive data such as demographics, grades, and interaction traces with online content (Pardo and Siemens, 2014), which students may be uncomfortable sharing or have used in learning analytics (Ifenthaler and Schumacher, 2016). The situation becomes even more muddled when third parties are involved in the collection and use of educational data. For instance, Learning Management System (LMS) vendors, such as Blackboard, have also turned to developing early warning systems and products that rely on educational data, even though such data sharing arrangements may be unclear to students (Polonetsky and Jerome, 2014). The manner by which data collection is conducted thereby creates a tension between institutional goals of using effective predictive models to support students' educational progress while upholding commitments to learners' agency and privacy (Prinsloo and Slade, 2014).

There have been numerous calls to provide students with more agency regarding how data is used in learning analytics (Pardo and Siemens, 2014; Drachsler and Greller, 2016). Yet, students' privacy concerns may deter them from consenting to the use of the data in learning analytics, which may undermine the performance of predictive models. Moreover, biases have been shown to exist in predictive models, partly due to non-representative samples acquired during data collection (Ocumpaugh et al., 2014). As the availability of data is restricted, machine-learned models may have a reduction in accuracy which can lead to less effective interventions for some (or all) students (Li et al., 2019). This is particularly concerning since demographic gaps already exist in educational achievement (Bainbridge and Lasley, 2002), which is es- 
pecially true for underrepresented minorities (Bensimon, 2005), those with a lower socioeconomic status (Duncan and Magnuson, 2005), and between genders in certain contexts such as STEM programs (Matz et al., 2017). Not only are there outcome discrepancies, but it has also been shown that different demographics-based communities have different expectations of privacy and concerns when it comes to how their data is to be used (Cho et al., 2009). If those in the minority are more reluctant to share data, this may lead to poor predictions for those in such groups, thereby exacerbating the problem and diminishing an institution's ability to provide the same quality of education for all.

In this study, we are investigating students' propensity to consent to or opt out of having their data collected and use for the purposes of learning analytics. We further connect consent propensity to students' demographics, personality characteristics, as well students' perspectives and concerns regarding learning analytics in order to understand the factors motivating students' expressed consent preferences. Linking participants' responses to demographic characteristics, enables us to analyze differences between student subpopulations and how that might translate into differential consent rates, thereby affecting the predictive models on which institutions rely. The research questions we address are as follows:

[RQ1]: What are students' perspectives on their educational data being used in learning analytics?

[RQ2]: What are the population and participation characteristics of students who indicate a preference to allow or disallow their educational data to be used for learning analytics?

We answer these questions by first ascertaining students' propensity to consent or deny use of their educational data for learning analytics with an email-based one-question preference elicitation prompt with Yes/No options. Respondents were subsequently invited to complete an online survey that investigated the factors behind their consent indication in order to identify key determinants. The email prompt and online survey responses were then associated with students' educational records in order to contextualize the relationship between students' demographic characteristics and their propensity to participate in learning analytics. We send our email prompt to a sample of 4,000 students at our institution stratified by ethnicity and gender; 272 students responded to the email prompt and 119 completed the survey.

We found differences in response rate to the email prompt among genders and ethnicities. Female students were much more likely to respond than male students and, despite stratified recruitment, responses from White students were overrepresented while responses from Black students were underrepresented; there were no differences in the consent proportion between genders nor ethnicities. Among respondents, we identified three important factors which play a role in students' consent expressions regarding learning analytics: student's trust in the educational institution, a student's level of concern regarding individual data collection, and a student's comfort with an instructor's use 
of data for teaching improvements. Certain privacy attitudes are correlated with population subgroups, most notably students' identifying ethnically as Black generally have less trust in the institution, and female students tend to have greater apprehension about personal data collection while simultaneously being comfortable with instructor use of such data. We find that instructors may have an important role in making students feel at ease when it comes to data sharing by being more transparent regarding who has data access and the purpose for its use, thereby balancing broader institutional interests of effectively educating students while maintaining individual privacy safeguards.

\section{Background and Related Work}

We discuss prior work on three topics that contextualize our findings and motivate our study design: factors impacting willingness to consent, disparities between demographic groups, and privacy concerns regarding learning analytics.

\subsection{Factors Impacting Willingness to Consent}

The issue of consenting to data collection has been studied in a variety of domains. In the business and e-commerce setting, consumers' likelihood to provide personal information has been shown to be related to the control they have over the ownership of their personal data (Goodwin, 1991), the company's privacy policy statement (Meinert et al., 2006), financial rewards (Olivero and Lunt, 2004), number of information recipients (Schudy and Utikal, 2017), and the framing of how consent is asked for (e.g., opt-out or opt-in) (Johnson et al., 2002; Samat and Acquisti, 2017). Similarly, we investigate in the educational context whether the extent students' propensity to consent to data collection and use for learning analytics is correlated with different demographics, specific institutional data uses, perceived benefits, privacy concerns, and how consent requests are presented to students.

In contrast to business settings, where perceived profit-driven motivations may affect consumer trust regarding data collection, studies in the medical research field found that people generally support such research. They are more willing to share personal health information if they are asked for permission or given the option to opt out, because it is considered a courtesy (Willison et al., 2007) and as respect for the individual (Willison et al., 2003). Trust is another factor as patients are more willing to consent to their data being used for research if they trust that the researchers will keep patients' information confidential, the organization will protect patients' privacy, and the patients will be informed how their medical records are being used for research (Mechanic, 1998; Purdy et al., 2000).

Different personal values such as privacy and perceived value of research also affect a participant's willingness to consent. For instance, Sala et al. (2012) 
identified that respondents' privacy attitude negatively affects their willingness to consent to health data being used when linking it to other administrative data (e.g. benefit receipt, morbidity). Ewing et al. (2015) discovered that people are less likely to accept either broad or narrow consent models for medical research when they have privacy concerns. Kim et al. (2017) identified that people are more willing to consent to the sharing of electronic health data for research when they believe that such an action will improve research quality, or that they value research benefit more than personal privacy. In this study, we demonstrate that some of these factors also apply to data sharing in higher education.

\subsection{Disparities Between Demographic Groups}

There exist disparities between demographic groups when it comes to consent. It has been shown that consenting to participation in research is related to socio-demographic characteristics such as age (Jacobsen et al., 2004; Benfante et al., 1989), gender (Ramos et al., 2004; Pirzada et al., 2004), socioeconomic status (Boshuizen et al., 2006; Gordon et al., 1959), ethnicity (Moorman et al., 2004, 1999), and health conditions (Gerber et al., 2007; Gordon et al., 1959). Individuals from underrepresented minorities have been found to be less willing to share their data (Nanibaa'A et al., 2016). As for ethnicity, comparing to those who identify as White, people who identify as Asian (Kaufman et al., 2009b), Black non-Hispanic (Kaufman et al., 2012, 2009a), AfricanAmerican (Chen et al., 2005), and Native Hawaiian (Fong et al., 2004) were less likely to accept researchers using their data without explicitly being asked for permission. The type of consent approach matters as it is found that younger patients and Hispanic patients have stronger preferences for opt-in consent compared to patients who are older or from different ethnic groups. (Kaufman et al., 2012).

Willingness to share data is affected by racial and ethnic differences and may be due to inequities between various groups. For instance, it is well recognized that there are disparities in the quality of health care received by patients with different racial and ethnic backgrounds; and such disparities result from factors such as broader social and economic inequalities, discrimination, bias, stereotyping, prejudice, clinical uncertainty, health insurance coverage, access to care and use of services, and patient treatment acceptance (Nelson, 2002; Chen et al., 2016; Buchmueller et al., 2016; Wasserman et al., 2019). In the employment market, racial and ethnic disparities generate gaps in hiring, promotion, satisfaction, and well-being (Emerson and Murphy, 2014). For instance, according to data from the Canadian Census, research found that Chinese-origin people, South Asian-origin workers, and Black workers all face significant earning disparity in the job market in that country (Pendakur and Pendakur, 2007).

Similarly, in education, the National Center for Education Statistics and other sources have shown that students from Hispanic/Latinx, African Amer- 
ican, American Indian, and Pacific Islander groups are underrepresented at all levels of higher education from undergraduate majors to graduate program pursuits, particularly in STEM-related fields (Hanson, 2008; Cook and Córdova, 2007). These underrepresented groups also have a greater high school drop out rate (Orfield et al., 2004). Even with successful graduation from higher education, individuals from minority groups are less likely to consider pursuing research career paths (DePass and Chubin, 2008). Faculty from minority groups have also been found to have slower rates of promotion compared to those who identify as White (Fang et al., 2000). This is of particular concern as an increasing number of technologies designed to help students rely on predictive models trained with educational records. These models have been shown to have bias, thereby performing poorly for populations which are not well represented (Li et al., 2019; Ocumpaugh et al., 2014). Coupled with the fact that minorities are less likely to consent in numerous contexts, it becomes crucial to understand these interactions in education to avoid developing models that inadvertently widen disparities.

\subsection{Privacy Concerns in Learning Analytics}

Predictive models have been used to identify students who are at-risk of failing or dropping out of a course, and to intervene early (Smith et al., 2012). However, because the effectiveness of these systems rests upon the collection of student data, including sensitive information and confidential records, this raises privacy concerns (Drachsler and Greller, 2016; Ifenthaler and Schumacher, 2016; Reidenberg and Schaub, 2018).

Privacy concerns are especially pertinent as technological advances have been met with breaches in public trust regarding the mismanagement of personal data, and this concern is reflected in regulations such as the General Data Protection Regulation (GDPR) or the California Consumer Privacy Act (CCPA). One consequence of these laws is that corporations must provide individuals with more agency regarding how data about them is collected and processed, as well as clarity as to the purpose for the data collection. This may lead people to disagree with having their data used in particular ways and increase the number of individuals who choose not to share data (Weippl and Min Tjoa, 2005), potentially worsening the issue of bias.

In the field of learning analytics, guidelines and checklists (Drachsler and Greller, 2016) of best practices have been developed to support institutions in using educational data in a responsible way, as studies suggest that students' are cautious when it comes to how their data are to be used, especially when they perceive this data to be more personal in nature, such as socioeconomic status (Ifenthaler and Schumacher, 2016). However, there are some distinctions as to the type of information that people are willing to share, and not all data is equally problematic. For instance, Sun et al. (2019) found that students were not necessarily opposed to the use of their data in an early warning system for 
advisors, but demanded more agency in decisions regarding how data about them is used.

However, such agency comes at the risk of decreased data and impacts predictive model performance. Li et al. (2019) showed in simulations the differential effect of student's opting out on the predictive power of learning analytics models for different student subpopulations; accuracy precipitously decreased for high simulated opt-out rates. A major limitation was the fact that students opting out of data sharing was simulated based on dropping a random sample, even though this is not likely the case in reality as there may be disparities in consent when considering demographics. We quantify students' participation and consent rates for learning analyitcs by demographic groups, which is important for contextualizing the differential effects identified by $\mathrm{Li}$ et al.. We further investigate the underlying reasons as to why people choose to consent or opt out of learning analytics, and how these factors are linked to demographic characteristics and personality traits.

\section{Methods}

Our study investigated two primary research questions: what are students perspectives on their educational data being used by learning analytics systems in the form of predictive models? (RQ1) and what are the population characteristics of students who indicate they would consent or opt-out of participating in such uses? (RQ2) In order to explore these questions we used an email-based preference elicitation prompt to assess consent propensity, administered a survey questionnaire about preferences and participation to respondents, linked the response data to demographic data, and analysed the results through regression models. Specifically, we distributed an email asking students whether or not they would hypothetically agree to have their data used in learning analytics systems. Upon selecting either yes or no to indicate their consent, students were redirected to an online survey that asked about the student's rationale behind their consent indication and perspectives regarding their data being used for leaning analytics purposes in different contexts and by different university stakeholders. We further elicited relevant personality characteristics and attitudes that might impact students' propensity to consent. Responses were then linked with institutional demographic and performance data as collected by the university to identify correlations with consent. This study design is summarized in Figure 1. In the sections that follow, we explain each part in greater detail. Our study was reviewed and approved by our Institutional Review Board.

3.1 Measuring Privacy Perceptions, Personal Traits, and Decision to Consent

To understand the factors in the decision to consent or opt-out of learning analytics use, we sent a one-question email prompt to a stratified student sample. 


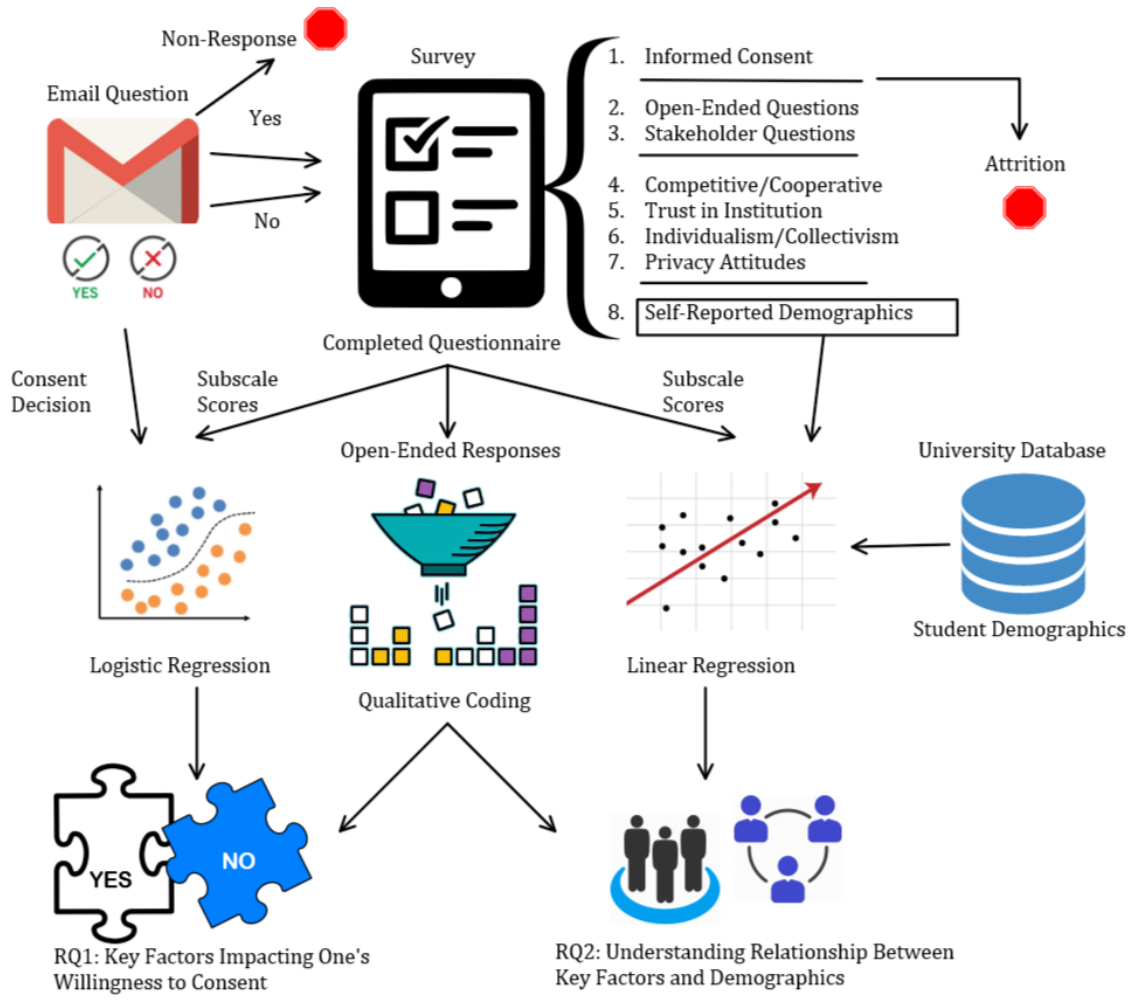

Fig. 1 Our study consisted of an email prompt sent to students that included links to the online survey, which consisted of multiple components. Email and survey responses were linked to institutional student records. The analysis methods are also shown along with the corresponding data that is needed for each approach in order to address our research questions.

Li et al. (2019) found that the use of either "opt-out" or "opt-in" wording leads to different response rates from participants. Thus, we prepared two variants of the email prompt, which were identical except for being framed as an "opt-in" or an "opt-out" decision. The email content is reproduced below:"

We are REDACTED researchers conducting a study to investigate student perceptions regarding the use of students' educational data in learning analytics systems.

Universities, including the University of REDACTED, are using learning analytics systems that measure, collect, analyze, and report data of learners and their contexts, for purposes of understanding and optimizing learning and the environments in which it occurs. Learning analytics systems use learners' data such as your grades, how you use online learning tools, your course registration information, and other

1 Certain aspects redacted for blind review. The text will be unblinded for publication. 
information about you to achieve different goals for different university stakeholders.

[Opt-out Wording:] If you were given a choice to opt out of having your student data used in learning analytics systems, would you? (Please click to indicate your choice)

Yes, I would opt out.

No, I would not opt out.

[Opt-in Wording:] If you were given a choice to opt into having your student data used in such learning analytics, would you?

Yes, I would opt in

No, I would not opt in

Once the student clicked either the yes or no link, the response was logged with an identifier to link with corresponding educational records. Identifiers were subsequently stripped before analysis to maintain anonymity as per approved Institutional Review Board oversight. Regardless of response, respondents were then directed to a debrief that explained the purpose of the study, an informed consent form, and an invitation to participate in an optional online survey. Participants who completed the online survey were compensated 5 USD.

The email prompt allowed us to ascertain propensities for students' consent to learning analytics data use. Our online survey further explored why such decisions were made. First, participants were asked in three open-response questions to describe the important factors that affected their decision, perceived benefits of student data being used learning analytics systems, and concerns with such data use. Next, we asked participants to rate their level of comfort on a seven-point scale with their educational data being used in five scenarios by different stakeholders for different purposes (e.g., "help instructors gain insights about students' engagement"). See Appendix A for the full survey instrument. We iteratively refined the wording of these questions to minimize misinterpretation, and pilot-tested the questions with two student groups.

We further assessed students' level of competitiveness and cooperativeness in the educational setting, using the Social Interdependence Scale (Johnson and Norem-Hebeisen, 1979), as this characteristic is an important evaluative factor in the college admissions process (Korn, 2019). The Social Interdependence Scale has three subscales with a total of 22 seven-point likert scale questions that measure student attitudes toward cooperative learning, competitive learning, and individualistic interdependence between oneself and others.

Given that students' trust in the institution has been shown to be a fundamental factor influencing students' learning experience (Van Maele et al., 2014), we wanted to understand whether students' institutional trust might impact their consent propensity. We adopted Ghosh et al.'s trust scale 2001, 
which is based on the defining trust as "the extent to which the students are confident to believe that the college will take the proper steps to help the students achieve learning and career goals." This trust scale consists of six subscales with a total of 39 seven-point likert scale questions measuring trust, expertise, congeniality, openness, sincerity, and integrity.

As our institution has a large body of international students with various cultural backgrounds, we identified students' level of individualism or collectivism as a characteristic that might differentiate their propensity for consent practices. We adopted the Horizontal and Vertical Individualism and Collectivism measurement scale by Triandis and Gelfand (1998), in which the individualism and collectivism characteristic indicates how people view the "self" from either the personal or collective view (Triandis, 1989), and influences how people prioritize personal goals versus group goals (Schwartz, 1990; Yamaguchi, 1994). There are four subscales that include 16 nine-point likert scale questions that evaluate horizontal individualism, vertival individualism, horizontal collectivism, and vertical collectivism.

Given that prior work has found students having privacy concerns regarding learning analytics (Pardo and Siemens, 2014; Picciano, 2012), we also included the 10-item, seven-point likert Internet User Information Privacy Concerns Scale (IUIPC) (Malhotra et al., 2004), which consists of three subscales for awareness of privacy practices, collection, and control.

Finally, we asked several demographic questions, including gender, ethnicity, first-generation college student status, and year of study in order to understand key factors in the decision to consent with regards to demographic characteristics.

\subsubsection{Alignment with Self-Reported Data}

Even though our institution collects demographics data and makes this available to researchers, we asked participants to optionally self report selected demographic information including year of study, gender, and ethnicity at the end of the online survey. This allowed students to self-identify as categories other than the one's prescribed whereas the survey includes non-binary gender options and specifications for countries of origin, and this also allows us to assess reliance of self-report data for this type of research by comparing one's stated demographics with official records stored by the university.

However, doing so means that there needs to be a way to reconcile differences between these two sources. For the purposes of modeling, we decided to go with the institutional records for both ethnicity and gender. For year of study, we use students' self-reported class standing. We discuss the reasoning behind this decision and the implications that our side analysis may have on data collection for similar research in Section 5. 


\subsubsection{Survey Recruitment 8 Participants}

Students were recruited based on specific demographic characteristics in the institutional database containing students academic records and demographic details. For each email variant (opt-in versus opt-out wording conditions) we recruited 2,000 students with no student receiving both versions of the survey (total emails sent was 4,000). Each sample of 2,000 students was selected using a disproportionate sampling method in order to ensure a more balanced data set. The population was first divided into 5 strata based upon the ethnic categories listed in the institutional data (White/Caucasian, Asian, Black/African, Hispanic/Latinx, and Other, which included those who indicated two or more ethnicities, Hawaiians, and Native Americans). Each stratum was also balanced with respect to gender ${ }^{2}$. This meant that each ethnicity-gender group had $n=552$ participants with the exception of Black/African students where the sample size was $n=342$ for both males and females due to scarcity.

\subsection{Quantitative Analysis: Modeling Factors in Consent Decisions}

We used a logistic regression model to control for the various factors outlined and to identify which considerations are most important in students' decision to consent. For the scales used, we computed a composite score based on items within each of its subscales. Importantly, this approach treats the ordinal measures as having continuous properties, but the trade-off posed by this assumption is offset by adopting a more stringent significance level and due to the relatively finer gradations in a 7 or 9-point Likert scale, which is true for all of the instruments that we reference in our survey. This procedure compressed the number of survey scale features to 24 . Note that the five comfort rating questions were used as-is (a discrete value in the set 1 thru 7 , inclusive). Full details of this analysis method along with models are found in the accompanying computer code in REDACTED.

\subsubsection{Ensuring Data Quality and Correctness}

To minimize errors due to low-quality answers, we checked survey responses for speeding and straightlining. Manual review of particularly fast and slow responses revealed no anomalies. Therefore, we choose to keep all responses.

We identified outliers and influential points by plotting Studentized residuals and Cook's distance for each observation, using an absolute value $>2$ and $4 /(N-k-1)$ as thresholds respectively, where $N$ is the total number of observations and $k$ is the number of explanatory variables. Studentized residuals are the residuals divided by estimates of the standard deviation, while Cook's distance summarizes the effect of removing an observation on the fitted response values. This resulted in 15 flagged points. Manual inspection made it evident

2 Institutional records only provided a male/female binary indicator 
that 2 people had accidentally selected a different option either by accident or due to a misunderstanding of the prompt. For instance, one explicitly stated that, "I misread the choices. As it said yes I assumed it meant to opt-in, not 'yes, I would opt out.' "; such answers were corrected. The remainder of the flagged items did not reveal any other evidently concerning issues. Removing all of these points results in quasi-complete separation and a large shift in the coefficients. Thus, it may be the case that those who denied use of their data were considered "unusual" solely because the overwhelming majority of students consented to data use for learning analytics; 15 of only 25 respondents who did not consent are in this list. We choose to retain these points in the model as they represent important perspectives to consider.

\subsubsection{Model Fit and Feature Selection}

We fit a logit regression model using maximum likelihood estimation. The predictor variables includes the 24 survey features, one for each subscale, described at the top of Section 3.2. The binary outcome variable was whether a student consented or denied the use of their data. Emphasizing the fact that we are interested in understanding specific factors, a feature selection processes was used for pruning the list of predictors into a smaller subset. This helps ensure that the significance values used to make these determinations are reliable, that confidence intervals on regression coefficients are sufficiently narrow, and violations of the linearity assumptions are addressed.

We used the variance inflation factor (VIF) as a gauge for multicollinarity and note that a number of features had a VIF above 5, indicating a problematic amount of collinarity. This is not necessarily surprising given that it is plausible to expect that some the measured concepts will be correlated to each other, particularly since we constructed composite scores based on subscales of an overarching latent trait. We alleviated this by conducting feature selection with recursive feature elimination (RFE) with 20-fold cross validation, which removes features iteratively based on feature importance, as well as backwards elimination (BE) with a threshold set at $p<0.05$, which removes features in accordance with the highest $\mathrm{p}$-values. We then choose the features common to both pruned models with $p<0.05$.

3.3 Quantitative Analysis: Modeling Relationships Between Key Consent Factors and Demographics

All demographic data was one-hot encoded for categorical variables (year of study, gender, and ethnicity into $N-1$ dichotomous variables where $N$ is the number of categories). We choose the category with the greatest population to exclude as a reference in the linear regression model. Therefore, a predictor was created for each demographic listed in Table 5 with the exception of "White", "Sophomore (2nd Year)", "Not First Generation", and "Male", which was our comparison group, resulting in a total of 8 one-hot encoded 
columns. The predictor variables are these 8 columns, while the target variable is the composite score for each of the $N_{f}$ key factors identified using the feature selection process described in Section 3.2.2. This results in a total of $N_{f}$ separate ordinary least squares models, one for each target variable.

Diagnostics were conducted for each of these models. There were no indications of collinearity; VIFs were below 2 for all factors and the matrix condition number was suitably low. Plotting the residuals against fitted values did not suggest any egregious outliers, nonlinear behavior, or major concerns regarding heteroscedasticity which may deflate p-values due to increased variance that is unaccounted for in the model. Thus, we are reasonably confident in our coefficients and statistical conclusions, described in Section 4.

\subsection{Qualitative Analysis}

We received 119 survey responses from the students. Nearly all of the students filled out the three open-ended questions (important factors affecting students' consent practices, benefits of allowing student data to be used for learning analytics, and concerns student have for such use). We engaged in successive rounds of open coding, where one researcher went through all responses and developed an initial codebook (Saldaña, 2015). The codebook was then refined iteratively by two of the authors independently coding a subset of responses and then jointly reconciling disagreement.. After four iterations, high interrater reliability (Cohen's $\kappa=.77$ ) was achieved. One researcher then used the final codebook to recode all responses to the three open-ended questions, a total of 348 responses from 119 participants. The final codebook was composed of 15 themes with 29 unique codes and is available in Appendix B.

\section{Findings}

Beginning with the quantitative analysis, we present statistics about response rates, show the key factors in willingness to consent and how these are correlated with demographics according to our regression models. The qualitative analysis is then presented, laying out factors, benefits, and concerns regarding students' views on data sharing, organized by subpopulations of students making similar statements.

\subsection{Quantitative Analysis Findings}

We break down our discussion of the quantitative analysis into three parts: statistics regarding participation rates during our initial email engagement with students, results regarding our logistic regression model used to identify primary factors underlying student's decision to share data (RQ1), and results from the linear regression models which explain demographic correlations with each identified factor of importance (RQ2). We find that there is both a gender 
and ethnicity gap between groups when it comes to response rate. The key factors identified behind the decisions of students who did respond were trust in the institution, level of general concern regarding individual data collection, and comfort with instructor use of data for classroom purposes. Institutional trust was generally higher for female students and lower for students who identify as Black, while data collection concerns and comfort with instructor data use were higher for females when compared to males.

\subsubsection{Response to Email Prompt}

Table 1 describes response rates split by email wording condition. Despite the low overall response rate of $6.8 \%$ we find that, generally speaking, most people $(72.4 \%)$ consent to data usage when they do respond. We do not find any effect on the participation rates (link clicks) between the opt-in and opt-out conditions. While the consent rate is somewhat lower for the opt-out condition; a two-tailed test for proportions shows that there is no statistical difference between these conditions $(p=0.39)$ when only considering those who made a selection. Therefore, for the remaining analysis, we combine the opt-in and optout conditions and look only at the aggregate data, given that the differences are negligible. This confirms the result in Li et al. (2019), which states that wording has no effect on participation rate, but contrasts with their findings regarding consent rate where a difference was found between conditions.

Table 1 Response rates per condition. The first two rows shows the number of emails sent out for each condition, and the number of people that clicked on a link (i.e. made an actual consent decision). The last two rows shows the number (and percentage) of respondents who consented or denied use of their data for those who responded to either the "opt-in" or "opt-out" condition via email link. "Overall" is a sum of the first two columns (both wording conditions).

\begin{tabular}{lccc}
\hline Emails Sent & $\begin{array}{c}\text { Opt-in Condition } \\
n=2000\end{array}$ & $\begin{array}{c}\text { Opt-out Condition } \\
n=2000\end{array}$ & $\begin{array}{c}\text { Overall } \\
n=4000\end{array}$ \\
\hline Link Clicks & $129(6.5 \%)$ & $143(7.2 \%)$ & $272(6.8 \%)$ \\
Consent & $101(78.3 \%)$ & $96(67.1 \%)$ & $197(72.4 \%)$ \\
Deny & $28(21.7 \%)$ & $47(32.9 \%)$ & $75(27.6 \%)$ \\
\hline
\end{tabular}

We can also decompose click rates to analyze participation by subpopulation, such as ethnicity and gender. The results of this analysis are presented in Table 2. There is a significant difference between the number of clicks or engagement between male and female participants (106 as compared to 166), even though we would expect these to be identical as the emails were stratified equally. Given those who did respond however, the consent rates do not deviate from expectation. A chi-squared test indicates that gender is independent of the consent rate, but this is not the case for number of clicks $\left(\chi^{2}=13.24\right.$, $p=0.0003$, Cramer's $V=0.22)$; there is a moderate association. 
Table 2 The number of link clicks and the number of people who consented to data use. The expected number of link clicks and consent rates were obtained by taking the aggregate click and consent rates, scaled by the total number of emails sent out according to subpopulation size (by gender or ethnicity). As mentioned previously in Section 3, this was balanced for gender and, to the greatest extent possible, ethnicity as well. Some adjustments were necessary due to the smaller proportion of students who identify as black.

\begin{tabular}{lccccc}
\hline & $\begin{array}{c}\text { Link Clicks } \\
\text { (Actual) }\end{array}$ & $\begin{array}{c}\text { Link Clicks } \\
\text { (Expected) }\end{array}$ & $\begin{array}{c}\text { Consent } \\
\text { (Actual) }\end{array}$ & $\begin{array}{l}\text { Consent } \\
\text { (Expected) }\end{array}$ & $\begin{array}{l}\text { Emails } \\
\text { Sent }\end{array}$ \\
\hline Male & 106 & 136 & 81 & 77 & 2000 \\
Female & 166 & 136 & 116 & 120 & 2000 \\
\hline White & 98 & 75 & 71 & 77 & 1108 \\
Asian & 72 & 75 & 57 & 52 & 1104 \\
Hispanic & 74 & 75 & 52 & 54 & 1104 \\
Black & 28 & 47 & 17 & 20 & 684 \\
\hline
\end{tabular}

A similar case holds for ethnicity: the consent engagement differs quite drastically between subpopulations, especially when compared with the expected number of link clicks. While Asian and Hispanic respondents' answers align with expectation (percent deviation of $-4 \%$ and $-1 \%$ respectively), there is a notable overrepresentation of responses from those identifying as White (by $31 \%$ ), and an underrepresentation of answers from those identifying as Black (by -40\%). Once again, we find that ethnicity is not independent from the click rate $\left(\chi^{2}=14.32, p=0.002\right.$, Cramer's $\left.V=0.13\right)$ with a medium effect size, whereas there is no such relationship with consent.

Given the aforementioned discrepancy, we ran a more particular test to see if there are true differences between the proportion of those who click on an answer within these subpopulations. Namely, we divide the sample into those who identify as Black and non-Black (case 1), as well as those who identify as White and non-White (case 2). The sample statistic in case 1 is -0.03 , with a $95 \%$ confidence interval (CI) of $[-0.053,-0.012]$, corresponding to $p=0.002$. For case 2 , the sample statistic is $0.028,95 \%$ CI of $[0.011,0.046]$, and $p=0.0015$. Therefore, the click proportion of each subpopulation when isolated in analysis is different from the leftover majority group. In other words, Black students participate less when compared to those those who are not Black, and White students participate more when compared to non-White students.

\subsubsection{Identifying Primary Factors in Participation}

In this section we explore the reasons behind these differential engagement by subgroup and address RQ1 by identifying the key factors that led to students' decision to consent or deny use of their data for those who did respond.

We fit a logit model where the predictor variables are the factors impacting students' willingness to consent with the binary outcome variable being whether or not a student consented or denied consent of the use of their data. Since the goal is to identify critical factors, our focus is not to achieve the highest predictive accuracy per se, though we present such summary statistics 
Table 3 This matrix shows the proportion of true labels to predicted labels. If we consider a positive label as being those who consent, then there were 92 cases where we predict one would consent and they actually did (true positives), 20 cases where people deny use and we predict that they would (true negatives), 5 cases where we predict one would consent but they choose not to (false positives), and 2 cases where we predict one would deny use of their data even though they consent (false negatives). The weighted F1 score is 0.94 .

\begin{tabular}{|c|c|c|c|}
\hline \multirow{3}{*}{$\begin{array}{l}\text { True } \\
\text { Label }\end{array}$} & & Deny & Consent \\
\hline & Deny & 0.80 & 0.20 \\
\hline & Consent & 0.02 & 0.98 \\
\hline
\end{tabular}

along with a confusion matrix in Table 3 to illustrate that our variables do have reasonable predictive power. Note that we also compute Cohen's $\kappa=0.81$ which indicates good agreement between the predicted and actual consent decisions.

Our final model was obtained by conducting feature selection using two techniques: recursive feature elimination (RFE) with 20-fold cross validation as well as backwards elimination (BE) with a threshold set at $p<0.05$ as described in Section 3.2.2. As BE yielded a feature subset of the RFE approach, we fit our model with the set from the most stringent standards and focus our discussion on the results of BE. Specifically, RFE results in 5 variables with $p<0.05$ (level of institutional trust, views regarding institutional integrity, concern regarding personal data collection, comfort of using data to benefit oneself, and comfort with instructors using data). BE indicates a subset of 3 factors that have an effect on the response variable and we consider the following to be impactful in students' decision to consent: one's trust in the institution, concern in the amount of personal data collected, and comfort with instructor use of data for instructional purposes. Table 4 shows summary statistics for the final model.

The odds ratios for each of these key factors may be interpreted in terms of a percent increase or decrease in the likelihood to consent to data usage given a one-point change in each particular subscale. Since all of the items in these three subscales are based on a 7-point Likert scale, a one-point increase in institutional trust means that students' likelihood to consent increases by $132 \%$. A one-point increase in comfort with instructor data use leads to a $212 \%$ jump, while concern regarding data collection by one point drops the chance of students consenting by $78 \%$.

\subsubsection{Demographic Correlations with Key Factors in Consent}

For each of the three key factors identified - institutional trust, data collection concern, and comfort with instructor data use - we then analyze correlations with demographic characteristics. First, we provide summary demographic 
Table 4 Summary of our logit model with three factors: institutional trust, the "Collection" subscale from IUIPC, and the self-developed stakeholder question regarding comfort with instructor use of data. Regression coefficients, standard error, z-score, p-value, and the lower and upper bound of a $95 \%$ confidence interval are given. In addition, we compute the odds ratio by exponentiating the coefficients.

\begin{tabular}{lccccccc}
\hline & Coeff. & $\begin{array}{l}\text { Std. } \\
\text { Error }\end{array}$ & $z$ & $P>|z|$ & {$[0.025$} & $0.975]$ & $\begin{array}{c}\text { Odds } \\
\text { Ratio }\end{array}$ \\
\hline Institutional Trust & 0.843 & 0.328 & 2.571 & 0.0100 & 0.200 & 1.486 & 2.324 \\
IUIPC Collection & -1.526 & 0.436 & -3.495 & 0.0004 & -2.381 & -0.670 & 0.217 \\
Comfort-Instructor & 1.1366 & 0.291 & 3.900 & 0.0001 & 0.565 & 1.708 & 3.116 \\
\hline
\end{tabular}

statistics for those who completed the survey in Table 5. Note that similar to the email engagement findings, the discrepancies between demographics is also present in the survey completion rates: students who identified as White or students who identified as Female students are overrepresented while students who identified as Black are underrepresented.

Table 5 Demographic counts for the number of students within each category for ethnicity, year of study, gender, and self-reported first-generation college student status. Note that Freshman are not included the university database only takes a snapshot of records at the end of a term whereas our survey was administered at the start. The total for each category adds up to 119, which is the total number of people that completed the entirety of the survey, but does not include those who clicked on the email but chose not to proceed.

\begin{tabular}{|c|c|c|c|}
\hline \multicolumn{2}{|c|}{ Demographic Statistics } & \multicolumn{2}{|l|}{ (Counts) } \\
\hline \multicolumn{2}{|c|}{ Ethnicity } & \multicolumn{2}{|l|}{ Year of Study } \\
\hline White & 49 & Freshman (1st Year) & $\mathrm{N} / \mathrm{A}$ \\
\hline Asian & 31 & Sophomore (2nd Year) & 65 \\
\hline Hispanic & 29 & Junior (3rd Year) & 42 \\
\hline Black & 10 & Senior $(4$ th + Year $)$ & 12 \\
\hline \multicolumn{2}{|l|}{ Gender } & \multicolumn{2}{|c|}{ First-Generation College Student } \\
\hline Male & 44 & Yes & 27 \\
\hline Female & 75 & No & 92 \\
\hline
\end{tabular}

To understand the potential reasons behind these differences we address RQ2 and identify correlations between demographics and influences impacting willingness to consent by running a linear regression model per key factor identified. The summary statistics for each model, where the outcome variables are the corresponding subscale scores, are tabulated in Table 6. For institutional trust, we find that identifying as female corresponds to higher levels of trust relative to males. The opposite is true for certain ethnicities: Black students are less trusting of the institution when compared to White students. Female students also correlate with having more data collection concerns, as measured by the IUIPC collection subscale, while having greater comfort with instructor use of data for course purposes. Finally, the collection score has an inverse 
relationship with those identifying as Asian (that is, students who identify as Asian not be as concerned with personal data being collected), although this effect is a slightly weaker claim given the larger p-value $(p=0.15)$.

Table 6 Summary statistics for each of three linear regression models with different target variables: institutional trust, IUIPC Collection subscale, and the stakeholder question for comfort regarding instructor data use. In all three cases, the predictors are demographic categories. Note that the reference groups mentioned in Section 3.3 are excluded, as this would be a linearly dependent column. Once again, the coefficients, errors, t-statistics, pvalues, and confidence interval bounds are provided. Factors of particular interest with a relatively low p-value are bolded, though no standard significance level is explicitly chosen.

\begin{tabular}{|c|c|c|c|c|c|c|}
\hline $\begin{array}{l}\text { Instl. } \\
\text { Trust }\end{array}$ & Coeff. & $\begin{array}{l}\text { Std. } \\
\text { Error }\end{array}$ & $t$ & $P>|t|$ & {$[0.025$} & 0.975 \\
\hline male & 0.384 & 226 & 1.696 & 09 & 0.065 & 32 \\
\hline t Gen. & & & .084 & & & \\
\hline unior & 0.067 & 230 & 0.293 & & & 0.522 \\
\hline nior & & & -0.613 & & & \\
\hline lack & 2 & 405 & -1.659 & 0 & 4 & 0.131 \\
\hline Asian & & .268 & 0.238 & 812 & 99 & 0.610 \\
\hline Hispanic & 0.065 & 0.275 & 0.238 & .812 & -0.479 & 0.610 \\
\hline $\begin{array}{l}\text { IUIPC } \\
\text { Collect. }\end{array}$ & C & $\begin{array}{l}\text { Std. } \\
\text { Error }\end{array}$ & $t$ & & {$[0.025$} & $0.975]$ \\
\hline emale & 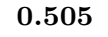 & 94 & 1.71 & 008 & -0.078 & 1.088 \\
\hline First Gen. & & & & & & 829 \\
\hline unior & & 99 & 0. & 1 & 2 & 32 \\
\hline enior & .02 & 478 & -0.060 & .9 & 5 & 0.918 \\
\hline & -1 & & $\rho$ & & & 1.019 \\
\hline & & & -1. & & & 0.186 \\
\hline Hispanic & 0.077 & 0.358 & 0.216 & 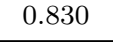 & 22 & 0.786 \\
\hline $\begin{array}{l}\text { Instruct. } \\
\text { Data Use }\end{array}$ & oeff. & $\begin{array}{l}\text { Std. } \\
\text { Error }\end{array}$ & $t$ & 10 & .025 & $0.975]$ \\
\hline & & & & & & \\
\hline Firs & & & -0.5 & & & 447 \\
\hline & & & 0.6 & & & 739 \\
\hline Senio & -0.401 & & -0.907 & 7 & & 0.476 \\
\hline & & & & & & 1.147 \\
\hline & & & & & & \\
\hline Hispanic & 0.176 & 0.332 & 0.530 & 0.597 & -0.481 & 0.833 \\
\hline
\end{tabular}

\subsection{Qualitative Analysis Findings}

We describe our findings from qualitative analysis in two parts. First, we introduce students' overall response to the important factors affecting their consent practices, as well as the benefits and concerns they view for allowing student data being used by learning analytics. We found that students recognised that allowing their student data to be used in learning analytics systems can 
beneficially contribute to improving education, supporting new research, and positively impacting more students, while students' also expressed concerns for data privacy, data collection and ambiguity around data usage. Second, based on the patterns we have identified through statistical analysis (e.g., trust in the institution, views on data collection, and comfort of student data for instruction use affect students' willingness to consent), we report here the corresponding qualitative findings. Namely, students who commented on trusting the institution all consented, while those who said they distrust the institution or the researchers denied consent. Students had varying views of data collection depending on the context of use of that data and the stakeholders involved. We further probed students' privacy perceptions which involved relevant views to data collection and found diverse connections. Students' responses revealed that they considered instructors as key stakeholders and users of student data, and valued the instructor use of this data.

Table 7 Decision factors reported by students who consented

\begin{tabular}{lrr}
\hline \multicolumn{1}{c}{ Factors Affected Students to Consent } & Count & Percentage \\
\hline Value data contribution to improve education/learning/teaching & 28 & $30.43 \%$ \\
Value data contribution for new understanding \& research insights & 19 & $20.65 \%$ \\
Positive impacts on other students and future generations & 19 & $20.65 \%$ \\
Value data contribution to support general research & 16 & $17.39 \%$ \\
Data privacy and security considerations considerations & 15 & $16.30 \%$ \\
Value data contribution to improve learning analytics systems/tools & 13 & $14.13 \%$ \\
Value data contribution for generic support & 13 & $14.13 \%$ \\
Neutral or no impact on student themselves & 13 & $14.13 \%$ \\
Value data contribution for data completeness and accuracy & 11 & $11.96 \%$ \\
No concerns & 11 & $11.96 \%$ \\
Other & 12 & $13.04 \%$ \\
Positive impact on the university & 7 & $7.61 \%$ \\
Positive impact on other people & 7 & $7.61 \%$ \\
Positive impact on student themselves & 6 & $6.52 \%$ \\
Generic mentioning privacy & 6 & $6.52 \%$ \\
Positive impact on faculties and staff & 5 & $5.43 \%$ \\
Survey compensation & 5 & $5.43 \%$ \\
Trust in the institution & 3 & $3.26 \%$ \\
Trust in the researchers & 2 & $2.17 \%$ \\
\hline
\end{tabular}

\subsubsection{Reported important factors in consent decision}

Among the 116 comments that answered the question regarding the important factors that affected students' consent decision, 92 related to positive consent decisions, and 24 to denied consent. For the 92 students who consented, we identified in these comments ${ }^{3} 19$ factors that affected their decision to consent (see Table 7). $30 \%$ of the students who consented mentioned that they value their data contributing to the improvement of education, learning, and teaching. A fifth of the students expressed their support for allowing student data

3 Some of the student comments include multiple factors. 
to be used for advancing understanding and research insights on student learning behaviors, teaching methods, etc., and $20 \%$ of the students stated that if using student data can help other students or future generations to learn, they would be willing to contribute their student data. Some students (17.4\%) also pointed out the importance of supporting research, indicating this was a factor which led them to consent. Around $16 \%$ of the students stated some levels of privacy considerations when deciding to consent, such as they valued privacy in general, they assumed that student data privacy is guaranteed by default, or they had privacy concerns but somehow still consented. Supporting the use of student data to improve learning analytic systems and tools $(14.1 \%$ of the students) and believing that allowing student data to be used is a purposeful and meaningful act (14.1\% of the students) were two factors students valued for their data to contribute to. For instance, one student said that "thinking about the greater good influenced my decision. If my student data can help improve quality of education overall, I would support its use." Roughly $14 \%$ of the students had a neutral response to the use of student data, writing comments such as "I have nothing to lose when giving my data", while $12 \%$ did not identify any concerns. $12 \%$ of the students believed that contributing to student data use is an important action to ensure data completeness and accuracy. The remaining factors in Table 7 were all mentioned by fewer than 10 had less than $10 \%$ of the students.

For the 24 students who denied consent (see Table 8), $63 \%$ expressed various privacy concerns (e.g., data breach, uncomfortable to share student data), and $20 \%$ expressed concern over the lack of transparency on how the data is collected, used, and analyzed, as well as who can access the data. $16.7 \%$ of the students talked about the lack of proper compensation to the students when their student data is used. $12.5 \%$ of the students were concerned about the potential negative impact that using student data could have on them, such as "I would be worried about my academic data being used in a way that negatively affects me." A few students denied consent due to their distrust in either the institution or the researchers. One student talked about the use of student data could cause harm to marginalized groups, and one student talked about the lack of student agency and control when student data is used.

Table 8 Distribution of factors from students denied consent

\begin{tabular}{lrr}
\hline \multicolumn{1}{c}{ Factors Affected Students to Deny Consent } & Count & Percentage \\
\hline Data privacy and security concerns & 15 & $62.50 \%$ \\
Lack transparency of data collection, access, analysis, and purpose & 5 & $20.83 \%$ \\
Lack compensation to use student data & 4 & $16.67 \%$ \\
Negative impact on student themselves & 3 & $12.50 \%$ \\
Misc. & 3 & $12.50 \%$ \\
Distrust in the institution & 2 & $8.33 \%$ \\
Distrust in the researchers & 1 & $4.17 \%$ \\
Negative impact on marginalized students & 1 & $4.17 \%$ \\
Data leakage concern & 1 & $4.17 \%$ \\
Lack control over student data & 1 & $4.17 \%$ \\
\hline
\end{tabular}




\subsubsection{Perceived Benefits of Data Use in Learning Analytics}

The benefits as to the use of student data for learning analytics which were identified by students, regardless of students' consent practices, are summarized in Table 9. The top three factors which students evaluated when they consented were the (1) value data contribution has to improve education, (2) support the use of student data for new research understanding and insights, and (3) use of student data can have a positive impact on other students and the future generation. These explanations were were given by $52 \%, 38 \%$, and $35 \%$ of the student respondents respectively. $21.7 \%$ of the students mentioned that allowing student data to be used can ensure data completeness for more accurate analysis, and $14 \%$ of the students explicitly expressed that they could gain positive impact from the use of student data by learning analytics with statements such as "I think it's important that my data be used to better improve and optimize our learning environments, which will benefit not only me, but the students that will be coming after me." Eight students (7\%) supported using student data to improve learning analytic systems and tools. Students also recognized that the use of student data could have different positive impacts on the university (8.7\% of the students), faculties and staff ( $7 \%$ students), and other people without specifying who (5.2\% of the students). A few students discussed the use of student data for good causes $(2.6 \%$ of the students), to support general researches (1.7\% of the students), and to positively impact society ( $1.7 \%$ of the students).

Table 9 Distributions of benefits in using student data

\begin{tabular}{lrr}
\hline \multicolumn{1}{c}{ Benefits of Using Student Data for Learning Analytics } & Count & Percentage \\
\hline Value data contribution to improve education/learning/teaching & 60 & $52.17 \%$ \\
Value data contribution for new understanding/research insights & 44 & $38.26 \%$ \\
Benefit other students and future generations & 40 & $34.78 \%$ \\
Value data contribution for data completeness and accuracy & 25 & $21.74 \%$ \\
Benefit student themselves & 16 & $13.91 \%$ \\
Benefit the university & 10 & $8.70 \%$ \\
Value data contribution to improve learning analytics systems/tools & 8 & $6.96 \%$ \\
Benefit faculties and staff & 8 & $6.96 \%$ \\
Neutral or no impact on student themselves & 7 & $6.09 \%$ \\
Benefit other people & 6 & $5.22 \%$ \\
Value data contribution for generic support & 3 & $2.61 \%$ \\
Benefit the society & 2 & $1.74 \%$ \\
Misc. & 2 & $1.74 \%$ \\
Value data contribution to support general research & 1 & $0.87 \%$ \\
Survey compensation & 1 & $0.87 \%$ \\
\hline
\end{tabular}

\subsubsection{Perceived Concerns Regarding Data Use in Learning Analytics}

For the concerns of using student data (see Table 10), over $60 \%$ of the students highlighted various types of data privacy and security concerns, such as "I'm a 
tad concerned that my data could be leaked to the general public. I like some privacy, so I don't really want everyone to have unfettered access to all my student data." $21 \%$ of the students worried about inaccurate interpretation or representation from the data and analytics. Unpredictable threats to student data such as data leakage or theft concerned 15 students (13\%). 11\% of students questioned the lack of transparency of the data collection, use, access, and analysis process. For instance, a student pointed out that "I am concerned about my privacy, who has access to my student data, and the real purposes for which it is being used (i.e. more than just for optimizing learning for the future)." While $11 \%$ of the students wrote "no concerns," another $10 \%$ of the students pointed out the negative impacts they might receive when student data is used by learning analytics, such as "I feel it would violate my privacy or that it might be used against me in some way." Some students were also uncertain about whether student data would be handled with confidentiality (6.8\% of the students), as well as insufficient students' agency and control of the student data ( $5.1 \%$ of the students students). One student indicated that the institution is not trustworthy to use the data responsively.

Table 10 Distributions of concerns in using student data

\begin{tabular}{lrr}
\hline \multicolumn{1}{c}{ Concerns of Using Student Data for Learning Analytics } & Count & Percentage \\
\hline Data privacy and security concerns & 71 & $60.68 \%$ \\
Inaccurate interpretation/representation from the data and analytics & 25 & $21.37 \%$ \\
Data breach/leakage/stolen & 15 & $12.82 \%$ \\
Lack transparency of data collection, access, analysis, and purpose & 13 & $11.11 \%$ \\
No concerns & 13 & $11.11 \%$ \\
Negative impact on student themselves & 12 & $10.26 \%$ \\
Confidentiality & 8 & $6.84 \%$ \\
Misc. & 8 & $6.84 \%$ \\
Lack control over student data & 6 & $5.13 \%$ \\
Distrust in the institution & 1 & $0.85 \%$ \\
Generic mentioning privacy (not concerns) & 1 & $0.85 \%$ \\
Lack compensation to use student data & 1 & $0.85 \%$ \\
\hline
\end{tabular}

\subsubsection{Students' Trust E Distrust in Institutions}

Our quantitative analysis revealed institutional trust to be a significant predictor of participants' consent. Among students who consented, four (3 whom identified as females, 1 whom identified as male) explicitly expressed their trust in the institution, mentioning its strong reputation, accountability, and research methods (e.g. to use data properly) respectively. Another student highlighted his positive belief that the researchers would be "handling my data appropriately and not abuse it." In contrast, two students (1 identifying as male, 1 identifying as non-binary), who denied consent, explicitly stated their distrust in the institution and the administration respectively. One of them noted they did not "trust the university to use this data in a way that 
won't hurt marginalized students." The second student who distrusted the administration does not believe that "the data wouldn't be used for commercial purposes." Additionally, two students (1 male, 1 female), who denied consent, said that they distrusted researchers because it is unclear how the researchers might use the student data, and the privacy risks and potential harms of the researchers' access to private student information.

Since our quantitative analysis showed that Black students generally have less trust in the institution, we analyzed all comments from participants who identified as Black to gain insights into their perspectives on having their student data being used. Of 9 Black students who completed the online survey (6 females, 3 males), 7 agreed to consent and 2 denied (1 male, 1 female). One student who denied consent expressed trust concerns: "I'm not sure what they're using the data for and I don't trust it." Most of the 7 students who consented discussed the positive impact of having their student data being use such as "potentially help another student in the future," "be more informative and beneficial on teaching/learning methods and tools than self-report," and "the university and other students can improve from analyzing my student data." These sentiments indicate a perception that the use of student data for learning analytics is generally beneficial.

\subsubsection{Student Perspectives on Data Collection}

As our quantitative analysis further showed that students' propensity to consent to learning analytics data use is negatively correlated with their concerns for data collection, we analyzed all open-ended responses that explicitly mentioned data collection. 9 female students and 1 male student wrote comments related to data collection. 2 female students, who did not consent, both mentioned being uncomfortable with sharing personal data as their reason for not consenting. One of them expressed additional privacy concerns: "I am not sure which information about me is being collected and analyzed and how will that information be applied to optimize learning... who would get access to my information and to what extent." The other 8 students, who all consented, expressed mixed attitudes towards data collection. The majority of them supported data collection for purposes such as better understanding students' performance trends and patterns, more accurate and representative results, the importance for research, and helping to improve student learning. This suggests that students who emphasize beneficial purposes of data collection are more inclined to consent.

Beyond the 10 students who explicitly mentioned data collection, we further looked at students' comments mentioning privacy. Malhotra et al. 2004 pointed out that the act of data collection, regardless of the format, is associated with privacy concerns. Thus, students' more general privacy concerns may help to shed further light on their attitudes toward data collection. 65 students (41 consented, 24 did not) wrote 92 responses mentioning privacy concerns. 72 of these comments were privacy concerns relevant to data collection concerns. 
33 of these students (20 consented, 13 did not) stated concerns about potential data misuse, and the lack of transparency on how student data is collected, who can access it, and how and with whom the student data in learning analytic systems is shared. There were no distinctive differences between answers from students who consented and those who did not. These students generally expressed concerns about (1) the possible abuse or misuse of student data by different entities (e.g., researchers or "the system") with different motivations (marketing, sale of information), and (2) uncertainty about how data may be used, accessed, stored, and shared. For instance, one student stated "what would happen after my data is used for its primary purpose? Does it just sit in a database, available to anyone for other use without my knowing or consent? Does it get deleted?" These concerns point at worries over lack of transparency.

The privacy concerns of 15 students (10 consented, 5 did not) focused on data security, leaks, and improper exposure. For the 5 students who denied consent, some mainly worried about the risk of student data being compromised if the system is not secure enough, others provided how their personal experience and attitude to the worldwide privacy and security issues affect their decision to not consent: "It feels like my data isn't safe with anyone...how can I trust any group when every day there are news stories about major platforms/companies failing their users, intentionally or not?" The $10 \mathrm{stu}-$ dents who consented mainly discussed worries about potentially unexpected data leakage, exposure, or hacking that might negatively impact students by putting them into vulnerable positions such as "use (the hacked student data) against me" or "it could affect my future job opportunities."

Another 11 students (9 consented, 2 did not) talked about risks of being identified. The students who denied consent stated that "the data won't stay anonymous" or "more people would know my information," which is similar to what those who consented said. However, we observed that students who consented tended to comment with a more trusting tone and frame their comments with a default belief that the collected student data would be aggregated and anonymized. It seems that students' internal assumption of whether the student data is de-identified and handled properly by the university plays part in affecting students' consent practices.

We noted earlier that students who expressed distrust in the institution all denied consent. It is worth noting that trust also came up in relation to privacy concerns related to data collection. Six students ( 2 consented, 4 denied) expressed their distrust or discomfort regarding data collection, use, and access. The four students who denied consent shared their discomfort with having their information being gathered and known by different parties: "I would prefer to not have my information (i.e., classes, my learning tools) being gathered. I feel a little uncomfortable," "I wouldn't trust other people looking at my personal information." In this case, students distrust and discomfort provides another angle to explain students' reluctant attitude toward data collection which is one of the driving factors influencing students' consent practice. 


\subsubsection{Views on Instructor Use of Student Data}

Our quantitative analysis revealed that students are more likely to consent to the use of student data by learning analytic systems if the purpose is to "help instructors gain insights about students' engagement." 9 students (7 consented, 2 did not) stated the benefits and importance of student data use by instructors. While some students believed instructors can use student data to improve teaching methods and optimize the learning process, others felt that instructors' use of student data can assist the instructors to gain better understanding of the different types of students to provide more personalized support and resources. It seems that students view instructors as key stakeholders and users of student data, and students are relatively more comfortable with such data use, which is positively related to their consent practice.

\section{Discussion}

We have found that there are three main factors that influence one's willingness to consent: degree of trust in the institution, concern regarding personal data collection, and comfort with instructors using data. Female students generally trust the institution and instructors when it comes to data use, despite having some reservations regarding individual data collection; Black students indicate lower trust levels towards the institution. We now discuss our findings' contributions to the knowledge regarding students' privacy perspectives and behaviors in an educational setting. First, we discuss how varying engagement rates may suggest that some students are not being well represented and highlight the importance of obtaining a representative sample. This leads into sources of error in our survey instrument, including considerations with the hypothetical nature of some questions and the reliability of self reports. Finally, we explore key factors and demographic trends in our findings, paying particular attention to the importance of instructors and discrepancies in trust between subpopulations. We also acknowledge limitations in extrapolating results due to our data collection setting and context dependencies regarding consent.

\subsection{The Difficulty Posed by Varying Engagement Rates}

As shown in Section 4.1.1, there is a difference in response rate by subpopulation. Namely, Black students responded to the email request at a significantly smaller percentage than expected, while responses from those identifying as White were overrepresented even when we account for differences in number of emails sent to each group. This is an important consideration as institutions who may be seeking input from students regarding data uses may be receiving a biased sample - not only because there are minorities in the population, but also because those who are underrepresented are even less likely to respond to a 
survey. Thus, enacting policy based on what might be perceived as a randomlysampled group, even if stratified or weighted to deal with group distributions, may inadvertently ignore minority opinion simply because there is lower rates of participation among such populations. This may undermine institutions in developing inclusive learning analytics interventions or approaches.

Thus, to avoid potential erosion of trust and tension around data usage, it may be beneficial to further explore the addition of nudging indicators or other designs to lessen this gap around response rate in student elicitation surveys that are meant to be inclusive. For instance, a future iteration to our email prompt could include a short paragraph explaining that it is invaluable for underrepresented students' to provide their input to avoid biases in predictive models and to improve the educational quality for all students. This may be presented to a random sample of students, or shown only to minority students. Other options may be varying levels of compensation based on subpopulations that are most lacking in data - paying for data which is scarce. It is important to not that here the focus is simply on getting people to select some option, and not to nudge them to choose to consent per se, though it is possible such changes could impact both response and consent rates.

\subsection{Survey Instrument: Sources of Error}

Another possible survey modification is to incorporate deception. Currently, the only necessary concealment component is that students are not told that their data is to be collected for the purposes of understanding the relationship between privacy perceptions and opt-out rates with their demographic characteristics; this is to prevent biasing the results. However, because students are answering a hypothetical question about whether or not they would allow use of their educational data for use in learning analytics systems, this might not align with their actual behavior in a situation with higher stakes, such as having to actually share their data in reality.

Consequently, mentioning a specific use case, such as an early-warning system that will be deployed in class to assist students when needed, may slightly shift students' decision to consent or increase the response rate due to greater perceived relevance and urgency. With that said, this must be weighed with ethical considerations and protocols, such as including a debrief immediately after and recognizing that it may have the side effect of diminishing the level of student trust in learning analytics research for some students, even if the risks are deemed to be minimal.

Along similar lines of trying to elicit authentic responses, we want to ensure the reliability of self-reported demographics. Yet, of the people who did not omit their response, there was a perfect agreement between the self-reports and university records for ethnicity, and a 98\% agreement for gender, and we expect that the gender discrepancy is because we supported a non-binary option in our survey while gender in our institution's records are still being reported dichotomously. The high levels of agreement also show that it may be 
possible to obtain accurate demographic information by only asking students to self report demographics without resulting in significant loss of data. Not only does this give students more agency over what they choose to share, it also suggests that one may be able to conduct similar studies requiring demographic information at other institutions, even if those details are not available to researchers or centrally stored.

\subsection{The Role of Instructors in Key Factors for Consent}

All three factors we identified as key in making a decision to consent, level of trust in the institution, general concern towards personal data collection, and comfort in instructor use of data, seem plausible and have intuitive explanations. It is probable that students who trust the institution and are more comfortable with instructors using data to improve classroom instruction would be more likely to share data. It is also not surprising that concerns regarding personal data collection would decrease the likelihood of such an occurrence. However, it is notable that of all the subscale measures and various stakeholders, instructor considerations are the most significant. This demonstrates that teaching faculty may have significant influence on how willing a student is to share their data, perhaps even overshadowing broader concerns about general data collection or institutional practices. It is especially plausible that institutional trust and comfortability with instructor are both key consent factors that influence each other, as prior studies have shown that a sense of belonging to the university affects retention and engagement (Zepke and Leach, 2010), among other factors, and that teacher-student relationships contribute to these feelings of rapport (Hagenauer and Volet, 2014). This might be explained by the fact that most students have more opportunities to form closer relationships with instructors and interact with them on a more frequent basis, whereas institutions may be attributed to administrators and other officials whose role and direct impact is less easily ascertained.

Some suggestions for tangible interventions include having the instructor provide more transparency when it comes to student data use in the classroom. For example, it may be that telling students what educational and demographic data is being collected, the purpose for its use, and the people who have access, may increase comfort with instructor use of data, thereby increasing the likelihood of consent as well. Similarly, having an instructor send an email prompt asking for students to consent or deny use of their data may elicit more people agreeing to share data as opposed what may been seen as a unilateral institutional action.

\subsection{Ethnicity and Gender Trust Gaps}

Finally, while it is more difficult to draw concrete conclusions between demographics and key factors in willingness to consent reported in the online 
survey due to lower sample sizes and overall power, some of the qualitative comments provide evidence in support of our quantitative results, such as the anticorrelation between institutional trust and students identifying as Black. Yet, there remains a fair number of Black students who did indicate some level of trust in the institution according to their open-ended responses. Discrepancies between gender displayed fairly strong signals when it came to all three key factors: trust in the institution, comfort with instructor data use, and overall data collection concerns. Specifically, we find that those who identify as female tend to trust the institution and instructors more, despite greater concerns regarding data collection as a whole. This may seem contradictory, though perhaps it is the case where those who identify as female are hesitant, but make an exception when data use is situated in an educational context due to trust in the institution and/or the instructor.

Therefore conducting a confirmatory analysis and identifying deeper rationale behind these cost-benefit considerations would be beneficial. Identifying whether certain factors outweigh others may be extracted in follow-up surveys and semi-structured interviews with specific groups of learners corresponding to student characteristics identified to be correlative with key factors such as Black, female, or students at the intersection of these identities. Questions about students' personal experiences at their university, relationship with instructors and other stakeholders, as well as personal beliefs and attitudes around data collection specifically would provide insights into what agency students desire with respect to learning analytics. It may also uncover whether these decisions are based on firmly ingrained biases or actionable concerns, and help contribute to a more realistic model of student choices and its effects on predictive modeling in learning contexts.

\subsection{Context Dependency and its Importance in Learning Analytics}

Even with extensions to uncover detailed patterns of reasoning through consent decisions, it is important to keep in mind that the dataset used in this study consists solely of records from a single larger university in the United States. Data collected at other institutions may have different underlying distributions and lead to distinct results with different conclusions. Conducting similar analyses at community colleges or other educational settings may help generalize the results of this paper, especially as Li et al. (2019) demonstrated a need to reevaluate predictive models when the training set for predictive models is altered. A cross-cultural survey administered at institutions around the world might allow for privacy expectations to be better understood.

Eventually, inter-institutional datasets compiled from various types of educational institutions around the world may be joined in order to refine opt-out simulations. One may obtain more specific estimates of data sharing ranges and demographics can be tied with students' responses to calculate various opt-out ranges, since different subgroups have different privacy perspectives and rates of participation as we have shown. The performance of predictive 
models may therefore incur greater differential effects, which will continue to necessitate further research to ensure there is a balance between maintaining trust and personal privacy while advancing education and ensuring fairness across diverse student populations.

\section{Conclusion}

In this study, we have addressed two critical questions regarding university use of students' educational data in learning analytics. RQ1 asked about students' perspectives on their educational data being used for learning analytics systems, and RQ2 sought to find the population and participation characteristics of students who indicated a preference to allow or deny such usage.

For RQ1, we have identified three primary factors: trust in the institution, concern with individual data collection, and comfort with instructor data use that influence a student's willingness to consent to their data being used in learning analytics. Higher levels of trust in the institution and greater comfort with the idea of instructors using educational data for instructional improvement correlate with much greater probabilities that a student will allow their data to be used for learning analytics. By contrast, more apprehension regarding personal data collection leads to a lower chance of consent.

Given these factors, we then explored RQ2 and found that female students were more likely to trust the institution and instructor data use than male students, but were also more generally concerned about data collection practices. Meanwhile, Black students indicated lower levels of institutional trust. We also note that female students had a higher response rate and that White students were overrepresented while Black students were underrepresented among people who made a consent decision.

While there are some limitations that come with survey instruments and the fact that this study was conducted at a single university, our findings surface important implications for institutions to consider when collecting data for learning analytics and we layout additional routes for confirming and generalizing the results presented here. We demonstrate that varying engagement rates might exacerbate the educational disparity between minority students and that instructors may have significant influence regarding students' consent decisions.

The findings for RQ1 and RQ2 illustrate that it is insufficient to only give students' agency and expect unbiased data. The differential response rates we identify show that perspectives from those who are underrepresented are still not properly accounted even when stratifying equally across groups. Additionally, the difference lies not only with consent rate, but also in the perspectives held by respective subpopulations; there are unique underlying perspectives that guide individuals' actions from each of these groups. Therefore, relying on such an approach for data collection is likely to continue producing biased predictions based on biased data, undermining the efficacy of educational technology and its potential to treat students fairly. In order to ensure the ethical 
use of AI in education, it is imperative to take note of students' major concerns and take steps to strengthen trust in their institution's numerous stakeholders through tangible actions such as implementing transparent data practices; allowing inequity to continue will only serve to increase mistrust, thereby lowering engagement and hindering institutions' ability to support all its students. Instead, by understanding the key factors that influence consent and their relation to students' personal background, institutions will be better equipped with the knowledge needed to enable technology-supported education while maintaining ethical data use and public trust.

\section{Acknowledgements}

Removed for blinded review.

\section{References}

Alhadad S, Arnold K, Baron J, Bayer I, Brooks C, Little R, Rocchio R, Shehata S, Whitmer J (2015) The predictive learning analytics revolution: Leveraging learning data for student success. EDUCAUSE Working Group

Arnold KE, Pistilli MD (2012) Course signals at purdue: Using learning analytics to increase student success. In: Proceedings of the 2nd international conference on learning analytics and knowledge, pp 267-270

Bainbridge WL, Lasley TJ (2002) Demographics, diversity, and k-12 accountability: The challenge of closing the achievement gap. Education and Urban Society 34(4):422-437

Baker R, Ocumpaugh J, Calvo R (2015) Interaction-based affect detection in educational software. New York: Oxford University Press

Benfante R, Reed D, MacLean C, Kagan A (1989) Response bias in the honolulu heart program. American journal of epidemiology 130(6):1088-1100

Bensimon EM (2005) Closing the achievement gap in higher education: An organizational learning perspective. New directions for higher education 2005(131):99-111

Boshuizen HC, Viet A, Picavet HSJ, Botterweck A, Van Loon A (2006) Nonresponse in a survey of cardiovascular risk factors in the dutch population: determinants and resulting biases. Public health 120(4):297-308

Buchmueller TC, Levinson ZM, Levy HG, Wolfe BL (2016) Effect of the affordable care act on racial and ethnic disparities in health insurance coverage. American journal of public health 106(8):1416-1421

Chen DT, Rosenstein DL, Muthappan P, Hilsenbeck SG, Miller FG, Emanuel EJ, Wendler D (2005) Research with stored biological samples: what do research participants want? Archives of Internal Medicine 165(6):652-655

Chen J, Vargas-Bustamante A, Mortensen K, Ortega AN (2016) Racial and ethnic disparities in health care access and utilization under the affordable care act. Medical care 54(2):140 
Cho H, Rivera-Sánchez M, Lim SS (2009) A multinational study on online privacy: global concerns and local responses. New media \& society 11(3):395416

Cook BJ, Córdova DI (2007) Minorities in higher education twenty-second annual status report: 2007 supplement. Tech. rep.

DePass A, Chubin D (2008) Understanding interventions that encourage minorities to pursue research careers. Bethesda, MD: American Council for Cell Biology

Drachsler H, Greller W (2016) Privacy and analytics: it's a delicate issue a checklist for trusted learning analytics. In: Proceedings of the sixth international conference on learning analytics \& knowledge, pp 89-98

Duncan GJ, Magnuson KA (2005) Can family socioeconomic resources account for racial and ethnic test score gaps? The future of children pp 35-54

Emerson KT, Murphy MC (2014) Identity threat at work: How social identity threat and situational cues contribute to racial and ethnic disparities in the workplace. Cultural Diversity and Ethnic Minority Psychology 20(4):508

Ewing AT, Erby LA, Bollinger J, Tetteyfio E, Ricks-Santi LJ, Kaufman D (2015) Demographic differences in willingness to provide broad and narrow consent for biobank research. Biopreservation and biobanking 13(2):98-106

Fang D, Moy E, Colburn L, Hurley J (2000) Racial and ethnic disparities in faculty promotion in academic medicine. Jama 284(9):1085-1092

Fong M, Braun KL, Chang R (2004) Native hawaiian preferences for informed consent and disclosure of results from research using stored biological specimens. Pac Health Dialog 11(2):154-159

Gardner J, Brooks C (2018) Student success prediction in moocs. User Modeling and User-Adapted Interaction 28(2):127-203

Gerber Y, Jacobsen SJ, Killian JM, Weston SA, Roger VL (2007) Participation bias assessment in a community-based study of myocardial infarction, 20022005. In: Mayo clinic proceedings, Elsevier, vol 82, pp 933-938

Ghosh AK, Whipple TW, Bryan GA (2001) Student trust and its antecedents in higher education. The Journal of Higher Education 72(3):322-340

Goodwin C (1991) Privacy: Recognition of a consumer right. Journal of Public Policy \& Marketing 10(1):149-166

Gordon T, Moore FE, Shurtleff D, Dawber TR (1959) Some methodologic problems in the long-term study of cardiovascular disease: observations on the framingham study. Journal of Chronic Diseases 10(3):186-206

Hagenauer G, Volet SE (2014) Teacher-student relationship at university: an important yet under-researched field. Oxford Review of Education 40(3):370-388

Hanson S (2008) Swimming against the tide: African American girls and science education. Temple University Press

Ifenthaler D, Schumacher C (2016) Student perceptions of privacy principles for learning analytics. Educational Technology Research and Development 64(5):923-938

Jacobsen SJ, Mahoney DW, Redfield MM, Bailey KR, Burnett Jr JC, Rodeheffer RJ (2004) Participation bias in a population-based echocardiography 
study. Annals of epidemiology 14(8):579-584

Johnson DW, Norem-Hebeisen AA (1979) A measure of cooperative, competitive, and individualistic attitudes. The Journal of Social Psychology 109(2):253-261

Johnson EJ, Bellman S, Lohse GL (2002) Defaults, framing and privacy: Why opting in-opting out. Marketing Letters 13(1):5-15

Jovanović J, Gašević D, Dawson S, Pardo A, Mirriahi N (2017) Learning analytics to unveil learning strategies in a flipped classroom. The Internet and Higher Education 33(4):74-85

Kaufman D, Murphy J, Erby L, Hudson K, Scott J (2009a) Veterans' attitudes regarding a database for genomic research. Genetics in Medicine 11(5):329

Kaufman D, Bollinger J, Dvoskin R, Scott J (2012) Preferences for opt-in and opt-out enrollment and consent models in biobank research: a national survey of veterans administration patients. Genetics in medicine 14(9):787

Kaufman DJ, Murphy-Bollinger J, Scott J, Hudson KL (2009b) Public opinion about the importance of privacy in biobank research. The American Journal of Human Genetics 85(5):643-654

Kim KK, Sankar P, Wilson MD, Haynes SC (2017) Factors affecting willingness to share electronic health data among california consumers. BMC medical ethics 18(1):25

Korn M (2019) College admissions group votes to allow more aggressive student recruiting. URL https://www.wsj.com/articles/college-admissionsgroup-votes-to-allow-more-aggressive-student-recruiting-11569701995

Li W, Brooks C, Schaub F (2019) The impact of student opt-out on educational predictive models. In: Proceedings of the 9th International Conference on Learning Analytics \& Knowledge, pp 411-420

Long T, Cummins J, Waugh M (2017) Use of the flipped classroom instructional model in higher education: instructors perspectives. Journal of computing in higher education 29(2):179-200

Malhotra NK, Kim SS, Agarwal J (2004) Internet users' information privacy concerns (iuipc): The construct, the scale, and a causal model. Information systems research 15(4):336-355

Matz RL, Koester BP, Fiorini S, Grom G, Shepard L, Stangor CG, Weiner B, McKay TA (2017) Patterns of gendered performance differences in large introductory courses at five research universities. AERA Open $3(4): 2332858417743754$

Mechanic D (1998) The functions and limitations of trust in the provision of medical care. Journal of Health politics, policy and Law 23(4):661-686

Meinert DB, Peterson DK, Criswell JR, Crossland MD (2006) Privacy policy statements and consumer willingness to provide personal information. Journal of Electronic Commerce in Organizations (JECO) 4(1):1-17

Miller TE, Tyree TM, Riegler KK, Herreid C (2009) Using a model that predicts individual student attrition to intervene with those who are most at risk. College and University 85(3):12

Moorman P, Newman B, Millikan R, Tse CK, Sandler D (1999) Participation rates in a case-control study:: The impact of age, race, and race of 
interviewer. Annals of epidemiology 9(3):188-195

Moorman PG, Skinner CS, Evans JP, Newman B, Sorenson JR, Calingaert B, Susswein L, Crankshaw TS, Hoyo C, Schildkraut JM (2004) Racial differences in enrolment in a cancer genetics registry. Cancer Epidemiology and Prevention Biomarkers 13(8):1349-1354

Nanibaa'A G, Sathe NA, Antommaria AHM, Holm IA, Sanderson SC, Smith ME, McPheeters ML, Clayton EW (2016) A systematic literature review of individuals perspectives on broad consent and data sharing in the united states. Genetics in Medicine 18(7):663-671

Nelson A (2002) Unequal treatment: confronting racial and ethnic disparities in health care. Journal of the National Medical Association 94(8):666

Ocumpaugh J, Baker R, Gowda S, Heffernan N, Heffernan C (2014) Population validity for educational data mining models: A case study in affect detection. British Journal of Educational Technology 45(3):487-501

Olivero N, Lunt P (2004) Privacy versus willingness to disclose in e-commerce exchanges: The effect of risk awareness on the relative role of trust and control. Journal of economic psychology 25(2):243-262

Orfield G, Losen D, Wald J, Swanson CB (2004) Losing our future: How minority youth are being left behind by the graduation rate crisis. Civil Rights Project at Harvard University (The)

Pardo A, Siemens G (2014) Ethical and privacy principles for learning analytics. British Journal of Educational Technology 45(3):438-450

Pendakur K, Pendakur R (2007) Minority earnings disparity across the distribution. Canadian Public Policy 33(1):41-61

Picciano AG (2012) The evolution of big data and learning analytics in american higher education. Journal of asynchronous learning networks 16(3):9-20

Pirzada A, Yan LL, Garside DB, Schiffer L, Dyer AR, Daviglus ML (2004) Response rates to a questionnaire 26 years after baseline examination with minimal interim participant contact and baseline differences between respondents and nonrespondents. American journal of epidemiology 159(1):94-101

Polonetsky J, Jerome J (2014) Student data: Trust, transparency, and the role of consent. Transparency, and the Role of Consent (October 1, 2014)

Prinsloo P, Slade S (2014) Student data privacy and institutional accountability in an age of surveillance. In: Using data to improve higher education, Brill Sense, pp 195-214

Purdy S, Finkelstein JA, Fletcher R, Christiansen C, Inui TS (2000) Patient participation in research in the managed care environment: key perceptions of members in an hmo. Journal of general internal medicine 15(7):492-495

Ramos E, Lopes C, Barros H (2004) Investigating the effect of nonparticipation using a population-based case-control study on myocardial infarction. Annals of epidemiology 14(6):437-441

Reidenberg JR, Schaub F (2018) Achieving big data privacy in education. Theory and Research in Education 16(3):263-279

Ritter S, Anderson JR, Koedinger KR, Corbett A (2007) Cognitive tutor: Applied research in mathematics education. Psychonomic bulletin \& review 14(2):249-255 
Sala E, Burton J, Knies G (2012) Correlates of obtaining informed consent to data linkage: Respondent, interview, and interviewer characteristics. Sociological Methods \& Research 41(3):414-439

Saldaña J (2015) The coding manual for qualitative researchers. Sage

Samat S, Acquisti A (2017) Format vs. content: the impact of risk and presentation on disclosure decisions. In: Thirteenth Symposium on Usable Privacy and Security (\{SOUPS $\} 2017)$, pp 377-384

Schudy S, Utikal V (2017) you must not know about meon the willingness to share personal data. Journal of Economic Behavior \& Organization 141:1-13

Schwartz SH (1990) Individualism-collectivism: Critique and proposed refinements. Journal of cross-cultural psychology 21(2):139-157

Smith VC, Lange A, Huston DR (2012) Predictive modeling to forecast student outcomes and drive effective interventions in online community college courses. Journal of Asynchronous Learning Networks 16(3):51-61

Sun K, Mhaidli AH, Watel S, Brooks CA, Schaub F (2019) It's my data! tensions among stakeholders of a learning analytics dashboard. In: Proceedings of the 2019 CHI Conference on Human Factors in Computing Systems, ACM, p 594

Tondeur J, Pareja Roblin N, van Braak J, Voogt J, Prestridge S (2017) Preparing beginning teachers for technology integration in education: Ready for take-off? Technology, Pedagogy and Education 26(2):157-177

Triandis HC (1989) The self and social behavior in differing cultural contexts. Psychological review 96(3):506

Triandis HC, Gelfand MJ (1998) Converging measurement of horizontal and vertical individualism and collectivism. Journal of personality and social psychology $74(1): 118$

Van Maele D, Forsyth PB, Van Houtte M (2014) Trust and school life. Rotterdam, The Netherlands: Springer

Wasserman J, Palmer RC, Gomez MM, Berzon R, Ibrahim SA, Ayanian JZ (2019) Advancing health services research to eliminate health care disparities. American journal of public health 109(S1):S64-S69

Weippl ER, Min Tjoa A (2005) Privacy in e-learning: anonymity, pseudonyms and authenticated usage. Interactive Technology and Smart Education $2(4): 247-256$

Willison DJ, Keshavjee K, Nair K, Goldsmith C, Holbrook AM (2003) Patients' consent preferences for research uses of information in electronic medical records: interview and survey data. Bmj 326(7385):373

Willison DJ, Schwartz L, Abelson J, Charles C, Swinton M, Northrup D, Thabane L (2007) Alternatives to project-specific consent for access to personal information for health research: what is the opinion of the canadian public? Journal of the American Medical Informatics Association 14(6):706-712

Yamaguchi S (1994) Collectivism among the japanese: A perspective from the self.

Zepke N, Leach L (2010) Beyond hard outcomes:softoutcomes and engagement as student success. Teaching in Higher Education 15(6):661-673 
Appendix A Debrief, Consent, and Survey Instrument

(After the student clicks on yes or no in the email, a new page pops up which contains more survey questions)

Thank you for your participation in the study!

Debrief on Study Purpose

In the previous email you were asked whether you would be willing to allow your data to be used or not for learning analytics systems. The goal of this study is to understand willingness and attitudes to share educational data by different subpopulations of students in order to ensure that future learning analytics systems are equitable and fair for all groups of students. For this reason, we are studying students' opt-in and opt-out propensity in combination with demographic information retrieved from their student records. This purpose was concealed in the email message to prevent biased responses. Please note that your response to the email and your demographic information obtained from your educational record are de-identified to protect your anonymity and privacy and cannot be linked back to you. As a result, it is also not possible to withdraw from the study (we would not be able to identify your response).

We'd like to ask you a few questions regarding your response, and this should take no more than 15 minutes to complete. This survey is anonymous. Responses will be used for academic research and may appear in publications about our findings. If you have further questions or concerns about the study, please contact our research team. Upon completion of the survey, you will be given a $\$ 5$ Mastercard gift card as a thank you for your time and participation.

To participate in the survey, please proceed to the next page...

Name of the Institution Consent for Student Participation in a Research Study

\section{Study Overview}

We invite you to a study that explores student perceptions regarding the use of students' educational data in learning analytics systems by filling out this survey which asks your perspectives on the use of student data in learning analytics and some demographic information. Taking part in this research project is voluntary. You do not have to participate, and you can exit the survey at any time. Please take time to read this entire form before deciding whether to take part in this research project.

\section{Purpose of This Study}

The objective of this study is to understand what factors might affect students' willingness to opt-out of having their educational data being used in learning analytics systems. 
3. Who can participate in the study

Participation in the study is through the email invitation you have received.

4. Information about study participation

If you complete the survey, your answers will be recorded. This takes about 20 minutes to complete.

5. Information about Study Risks and benefits

There are no known risks associated with this study. However, because this study collects information about you, there is potential for a breach of confidentiality (see below for protection mechanisms). This study will help us and other [Name of the Institution] educators better understand how to use educational data to build services for students like you.

6. Ending the Study

You are free to exit the survey at any time without penalty or cost.

\section{Financial Information}

For your completion of the study, you will receive $\$ 5$ gift card by mail. All information collected on the remuneration form will not be connected to your survey responses.

8. Protecting and sharing research information

Only authorized study team members will have access to collected data using approved university systems. After linking responses to educational records all identifiable information will be removed. Anonymized data may be retained for future studies.

\section{Contact Information}

Please contact the researchers listed below to obtain more information about the study or express any concerns you may have.

If you have questions about your rights as a research participant, or wish to obtain information, ask questions or discuss any concerns about this study with someone other than the researcher(s), please contact the following:[Name of the Institution] Health Sciences and Behavioral Sciences Institutional Review Board (IRB-HSBS) 
Beginning of the Survey Question:

Learning analytics are systems that measure, collect, analyze, and report data of learners and their contexts, for purposes of understanding and optimizing learning and the environments in which it occurs.

- In your response to the email, you indicated that you choose to opt into (or opt out of) having your student data being used by learning analytics systems, please describe the important factors that affect your decision. [blank for students to fill]

- In your response to the email, you indicated that you choose to opt into (or opt out of) having your student data being used by learning analytics systems, please describe the important factors that affect your decision. [blank for students to fill]

- What do you see as the benefits of having your student data being used by learning analytics systems? [blank for students to fill]

- What do you see as the concerns of having your student data being used by learning analytics systems? [blank for students to fill]

- There are different stakeholders at the university when it comes to how students' data are used. Consider how comfortable or uncomfortable you are with the following scenarios: [Extremely Uncomfortable (1), (2), (3), Neutral(4), (5), (6), (7)Extremely Comfortable] My educational data is used in learning analytics systems to

help me monitor my course activities.

help other students monitor their course activities.

help instructors gain insights about students' engagement.

help academic advisors monitor individual student performance.

help administrators understand student enrollment and academic achievement.

- We're interested in learning more about how you interact with other students. Please indicate to what extent the following statements describe you? [Completely false $=1,2,3,4,5,6$, Completely true $=7$ ]

I like to help other students learn.

I like to share my ideas and materials with other students.

I like to cooperate with other students.

I can learn important things from other students.

I try to share my ideas and materials with other students when I think it will help them.

Students learn lots of important things from each other.

It is a good idea for students to help each other learn.

I like to do better work than other students. 
I work to get better grades than other students do.

I like to be the best student in the class.

I don't like to be second.

I like to compete with other students to see who can do the best work. I am happiest when I am competing with other students.

I like the challenge of seeing who is best.

Competing with other students is a good way to work.

I don't like working with other students in school.

I like to work with other students. (reverse)

It bothers me when I have to work with other students.

I do better work when I work alone.

I like work better when I do it all myself.

I would rather work on school work alone than with other students.

Working in small groups is better than working alone. (reverse)

Next we'd like to learn more about you.

- Please indicate to what extent the following statements describe you? $[1=$ never or definitely no, $2,3,4,5,6,7,8$, and $9=$ always or definitely yes]

I'd rather depend on myself than others.

I rely on myself most of the time; I rarely rely on others.

I often do "my own thing."

My personal identity, independent of others, is very important to me.

It is important that I do my job better than others.

Winning is everything.

Competition is the law of nature.

When another person does better than I do, I get tense and worked up.

If a peer gets a prize, I would feel proud.

The well-being of my peers is important to me.

To me, pleasure is spending time with others.

I feel good when I cooperate with others.

Parents and children must stay together as much as possible.

It is my duty to take care of my family, even when 1 have to sacrifice what I want.

Family members should stick together, no matter what sacrifices are required.

It is important to me that I respect the decisions made by my groups.

(Note: for the statement "When another person does better than I do, I get tense and aroused." We changed the wording "aroused" to "worked up" based on feedback from survey pilot testing. We also revised the wording of the question prompt to be clearer.)

Next, we are interested in learning about your relationship with the university. 
- In the following questions, "employees" may refer to any faculty, instructors, staff, or administrators at [Institution Name]. Please indicate to what extent do you agree or disagree with the following statements? (1=Strongly Disagree, 2, 3, 4, 5, 6, 7=Strongly Agree)

Since I am unable to personally monitor all of [Institution Name]'s activities, I rely on the employees of the college to get the job done right.

I have faith in college employees to do those things that relate to my education at [Institution Name] that I cannot do myself.

I am confident that college employees do those things that relate to my education at [Institution Name] that my family cannot do for me.

(R)In general, I do not have confidence in [Institution Name].

I believe [Institution Name] is a credible organization.

I feel that I can rely on [Institution Name].

I believe [Institution Name] is capable of designing academic programs that meet student needs.

I believe [Institution Name] employees are experts in the positions that they hold.

(R)Generally speaking, [Institution Name] employees are untrained.'

People with relevant work experience are employed in all areas at [Institution Name].

[Institution Name] does things competently.

(R)Unfortunately, [Institution Name] does things poorly.'

[Institution Name] employees perform their tasks with skill.

[Institution Name] does things in a capable manner.

(R)[Institution Name] is not sympathetic to my needs.'

I believe that [Institution Name] is a friendly college.

In general, I like the attitudes of [Institution Name] administrators, faculty, and staff.

[Institution Name] treats me in a friendly manner.

(R)[Institution Name] employees treat others better than they treat me.'

[Institution Name] will always deal with me in a friendly manner.

[Institution Name] attempts to develop a friendship with me.

[Institution Name] uses its knowledge and experience to clear the confusion of the educational process.

[Institution Name] employees tell me what they are thinking.

[Institution Name] employees tell me what is on their mind.

Employees at [Institution Name] share their thoughts with me.

(R)[Institution Name] keeps information from me.'

[Institution Name] is sincere in what it promises to students.

I believe that [Institution Name] is honest when dealing with me.

I believe that [Institution Name] will always be honest in its associations with me.

[Institution Name] follows through on promises made to me.

(R)Keeping promises is a problem for [Institution Name].'

If [Institution Name] promises something to me, they will stick to it. 
Academically, [Institution Name] does things that they promise to do for me.

[Institution Name] does not hold academic integrity as a standard by which to live.'

[Institution Name] strives to be a perfect academic organization.

[Institution Name] always tells me the truth.

[Institution Name] employees would not lie to me.

[Institution Name] deals honestly with me.

(R)Sometimes [Institution Name] does dishonest things.'

(Note: we added a preface to explain the purpose of the questions, and we added a definition for "Institution Name employees" based on feedback from survey pilot testing)

Next we'd like to learn more about you.

- Please evaluate to what extent you agree or disagree with the following statements [(1=Strongly Disagree, 2, 3, 4, 5, 6, 7=Strongly Agree)]

Consumer online privacy is really a matter of consumer's right to exercise control and autonomy over decisions about how their information is collected, used, and shared.

Consumer control of personal data lies at the heart of consumer privacy.

I believe that online privacy is invaded when control is lost or unwillingly reduced as a result of a marketing transaction.

Companies seeking information online should disclose the way the data are collected, processed, and used.

A good consumer online privacy policy should have a clear and conspicuous disclosure.

It is very important to me that I am aware and knowledgeable about how my personal information will be used.

It usually bothers me when online companies ask me for personal information.

When online companies ask me for personal information, I sometimes think twice before providing it.

It bothers me to give personal information to so many online companies.

I'm concerned that the online companies are collecting too much personal information about me.

- What's your gender:

Woman

Man

Non-binary

Prefer not to disclose

Prefer to self-describe

- What is your year in your current university program ? 


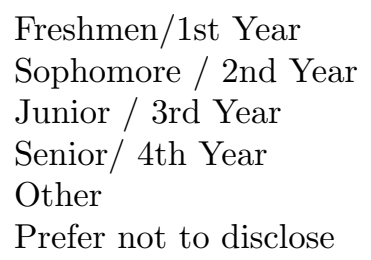

- Are you a first-generation college student? (Definition: No parent or guardian in the household has a bachelor's degree)

Yes

No

Prefer not to disclose

Are you of Hispanic, Latino, or Spanish origin? Yes(skip Q13) No Prefer not to disclose

- Which of the following racial or ethnic group(s) do you identify yourself as? [Mark all that apply]

American Indian or Alaska Native

White

Asian

Middle Eastern or North African

Black or African American

Native Hawaiian or Other Pacific Islander

Prefer not to disclose

Other [blank to fill]

- I am a

Domestic student [skip Q15]

International student [to Q15]

Prefer not to disclose

- I am from

(list of countries)

Prefer not to disclose

Thank you for your time and input! Your response has been recorded! 
Appendix B Codebook for Open-Ended Questions

Layer 1 Code: Value Data Contribution

\begin{tabular}{l} 
Layer 2 Code \\
\hline For data completeness \\
and accuracy \\
\\
\\
For new understand- \\
ing/research insights \\
(education, learning, \\
teaching, student \\
behavior)
\end{tabular}

For supporting general research (no specification)

For improving or supporting learning analytics systems/tools

For improvement of education or learning/teaching

For generic support (good causes/purpose, importance)
Definition Mention that people should contribute their data, or just for the sake of completeness. Has to have an emphasis between a single point or partial set of data vs a total/whole dataset in a broader context. When students say without their data the learning analytics/analysis won't be complete or accurate, or that having more data would lead to improvements.

When students say the use of student data can help understand or gain insights or research about anything related to learning, education, students' behaviors, backgrounds, situations, performances etc. It is about understanding of the current situation or issues without specifying the goal is to improve something. If students mention "improving" any aspect, code under improve education/learning/teaching environment/experiences"

Code here when students don't specify the goal of the research. When students say they want to help research/researcher, they value research, they want to be a part of the research by contributing their data, or they think research is important.

When students think positively of learning analytics/tools, and want to help improve learning tools. The "system" here is not the invisible education system, but an actual digital system. When students say help/improve (students) learning, (teachers)teaching, education experiences or environment. Referring to make things better.

When students generically say "purpose", "(good) cause", "it's beneficial", "it's important", etc. without other explanation.

Layer 1 Code: Trust 


\begin{tabular}{l|l} 
Layer 2 Code & Definition \\
\hline Trust in Institution & $\begin{array}{l}\text { When students mentions they have trust in the } \\
\text { university or the institution. When you see the } \\
\text { word "trust" or other ways to show beliefs and } \\
\text { faith in such concepts } \\
\text { Then students mentions they have trust in the } \\
\text { Tesearchers. When you see the word "trust" or } \\
\text { other ways to show beliefs and faith in such } \\
\text { concepts }\end{array}$
\end{tabular}

Layer 1 Code: Distrust

\begin{tabular}{|c|c|}
\hline Layer 2 Code & Definition \\
\hline Distrust in Institution & $\begin{array}{l}\text { When students mention they don't trust the } \\
\text { university or the institution. When you see } \\
\text { "don't trust" or "distrust" or other ways to } \\
\text { show disbelief and lack of faith in such con- } \\
\text { cepts }\end{array}$ \\
\hline Distrust in Researchers & $\begin{array}{l}\text { When students mention they don't trust the } \\
\text { researcher or research. When you see "don't } \\
\text { trust" or "distrust" or other ways to show dis- } \\
\text { belief and lack of faith in such concepts }\end{array}$ \\
\hline
\end{tabular}

Layer 1 Code: Positive Impact/Benefits on Other Parties

\begin{tabular}{l|l} 
Layer 2 Code & Definition \\
\hline Other Students & $\begin{array}{l}\text { Positive impact/benefits on other students. } \\
\text { Also include "future students" here. } \\
\text { Faculty/Staff }\end{array}$ \\
University & Positive impact/benefits on faculty/staff \\
Society & Positive impact/benefits on society \\
Others & When students don't specify the stakeholders \\
& but generally says "benefit others or someone".
\end{tabular}

Layer 1 Code: Negative Impact on Other Parties

Definition: Negative impact on other students

Layer 1 Code: Impact on Students Themselves 


\begin{tabular}{l|l} 
Layer 2 Code & Definition \\
\hline Positive impact on stu- & $\begin{array}{l}\text { This includes only positive impacts on student } \\
\text { themselves. Students have to specify "them- } \\
\text { selves" in the statement. Include statements } \\
\text { like "it will benefit me". If they refer to stu- } \\
\text { dents in general, don't code here, but code un- } \\
\text { der impact on other parties. } \\
\text { This includes only negative impacts on student } \\
\text { themselves. Students have to specify "them- } \\
\text { selves" in the statement. Include statements } \\
\text { student themselves } \\
\text { like "it will be used against me". If they re- } \\
\text { fer to students in general, don't code here, but } \\
\text { code under impact on other parties. } \\
\text { This includes only neutral impacts on student } \\
\text { themselves. Students have to specify "them- } \\
\text { selves" in the statement. Include statements } \\
\text { like "it won't affect me" or "no impact on me". } \\
\text { If they refer to students in general, don't code } \\
\text { here, but code under impact on other parties. }\end{array}$
\end{tabular}

Layer 1 Code: Privacy

\begin{tabular}{|c|c|}
\hline Layer 2 Code & Definition \\
\hline $\begin{array}{l}\text { Data Privacy \& Secu- } \\
\text { rity Concerns or Con- } \\
\text { siderations }\end{array}$ & $\begin{array}{l}\text { This includes statements have the word "pri- } \\
\text { vacy", "private", "personal", or any other syn- } \\
\text { onymous, and show concerning perspectives. } \\
\text { This include concerns about inappropriate data } \\
\text { access, use, storage and tracking. Code here } \\
\text { when data safety is mentioned, or whether they } \\
\text { feel safe about their data or not. It could be ei- } \\
\text { ther students' personal data safety or the gen- } \\
\text { eral data safety. It is not about students' phys- } \\
\text { ical safety. If student mention anonymity, code } \\
\text { here. }\end{array}$ \\
\hline $\begin{array}{l}\text { Generic Mentioning } \\
\text { Privacy (not concerns) }\end{array}$ & $\begin{array}{l}\text { Student might mention their perspectives or at- } \\
\text { titude toward privacy. They might only say "I } \\
\text { value privacy". Code such statements here. If } \\
\text { student says "I have privacy concerns", don't } \\
\text { code here and code under "specific privacy con- } \\
\text { cerns" }\end{array}$ \\
\hline
\end{tabular}

Layer 1 Code: Confidentiality

Definition: Code only when you see students mention concepts like "confidentiality" or "confidential". May be that the students think data/information confidentiality is important or that they have data/information confidentiality concerns. 
Layer 1 Code: Data Stolen/Breaches/Leakage

Definition: When students mention data stolen, breaches, leakage concepts specifically

Layer 1 Code: Lack Transparency (on Data Collection, Access, Use, Storage, Flow, Tracking, Analysis, Interpretation, Algorithm)

Definition: Any time the students say, "I don't know/it's unclear how data is collected, accessed, used, stored, analyzed, and interpreted by who." If they are worried about selling of the data, code here as well.

Layer 1 Code: Inaccurate Interpretation/Representation from the Data and Analytics

Definition: Students worry the data analysis provides an inaccurate representation of the students. Code when students say somethings like "the system can't represent my grade, or I may not be representative of other students." This is different from interpretation. Code as negative impact as needed.

Layer 1 Code: Lack Agency/Control/Consent

Definition: When students worry about consent; state there is no control of the data, no permission asked, or that they are not involved in the data process

Layer 1 Code: Data Value/Compensation

Definition: When students think their data has value; they want some compensation/benefit

Layer 1 Code: No Concerns

Definition: When students say "I don't have any issue", "no concerns/risks," etc. The difference between "no impact" and "neutral impact on student themselves" is that no concern is very general, without saying anything about the students themselves. Also includes those who assume that this information is public or not personal, or "don't care".

Layer 1 Code: Miscellaneous

Definition: Other things that do not fit into the other categories. If only part of the statement seems fit in MISC, other parts of the statements can be labeled with other codes. Also, code the whole statement here. 